\title{
Cultural Routes : Theoretic System And Its Enlightenment To China Heritage Practice
}

\author{
Zhewen BAN ${ }^{1, a}$ Feihu $\mathrm{CHEN}^{2, \mathrm{~b}}$ Tingqi $\mathrm{BAN}^{3, \mathrm{c}}$ and Cong BAN ${ }^{4, \mathrm{~d}}$ \\ ${ }^{1}$ Architecture School and Design Art School of HUNAN University, Changsha 410082,China \\ ${ }^{2}$ Architecture School of HUNAN University, Changsha 410082,China \\ ${ }^{3}$ Housing and Urban-Rural Construction Bureau of Enping Government, Enping 529400,China \\ 4 Hualan Design \& Consulting Group , Nanning 530000 ,China \\ abanzhewen@hotmail.com*, b188000786@qq.com ,'jmbake@21cn.com, d24823621@qq.com
}

Keywords: cultural heritage, linear cultural heritage,cultural route, integrity protection

Abstract. Cultural routes, as a kind of innovative cultural heritage protection concept is a linear cultural phenomenon with its large scale, cross-regional and cross-cultural features, the most core concept of this heritage type is the integrity linear protection and management along with its tangible elements and intangible cross-cultural background in the integrity and authenticity content .Cultural routes theory went through a history of discussion, development and perfection by more than ten years since 1994 when this concept was promoted at the first time to the world .In 2008, ICOMOS released the "ICOMOS Charter on Cultural Routes "in the 16th General Assembly, which completely interpreted the cultural routes ' connotation and definition, heritage content and its authenticity and integrity standard, its heritage integrity management and its relationship with local sustainable tourism.Through the comprehensive analysis to culture routes theory ,the paper points out its beneficial enlightenment to China heritage conservation by its innovative measures such as integrity heritage concept, sustainable tourism development and coordinated management .

\section{Introduction}

Cultural routes has caused widespread attention as a kind of innovation cultural heritage concept with its large scale, cross-regional, cross-cultural and linear characteristics in the world heritage practice and theory community. It reflects a new cultural heritage conservation trend from "point" protection to "surface" protection, from tangible environment protection to intangible environment background context protection..$^{[1]}$

Cultural routes protection concept plays a more and more important role in the world heritage protection work. it has a realistic significance for Chinese heritage protection. In recent years, China's domestic academia introduces this theory and research into the China' specific routes practice case such as the silk road, the grand canal of China, tea horse route of China . They have made a beneficial discussion to China cultural routes heritage protection work.

However, the current domestic scholars tend to intercept theory content based on uncompleted cultural route meeting results, with this uncompleted concept understanding, differences are mixed out with the conception confusion.It lack of a complete theory analysis system to its concept 's development process,significance understanding and theory analytic aspects .

Because of above, basis on the predecessors' related theories and literature review written in English or in Chinese, this paper provide a holistic analysis to cultural routes 'theory evolution, theoretical connotation and its enlightenment to China theory and practice .

\section{Theory Evolution of Cultural Routes}

Cultural route is a new type of heritage. The concept of cultural routes can be traced back earlier to the 1993 when the San Diego route was listed as the world heritage line according to the research of ICOMOS, This kind of cultural heritage type is without precedent at that time. 
In November of 1994, the Spanish government funded for the world heritage experts' culture route meeting at Madrid , entitled "cultural route" as part of our cultural heritage , expert meeting report made a define foundation for the concept of cultural routes.$^{[2]}$

In 1998, ICOMOS set up the International Scientific Committee on Cultural Routes (CllC).

In 2001, CllC published the book «The Intangible Heritage and Other Aspects of Cultural Routes», discussed in detail on the theory circuit and concept about cultural routes, emphasized the status role of immaterial heritage in cultural routes heritage system .

In 2002, CllC reached consensus in the science conference at Madrid.

In 2005, cultural routes became as a special type of heritage in the revised edition of operational guidelines of world heritage convention, and became the one of the four assembly issues on the 15 th ICOMOS meeting agenda. ${ }^{[3]}$

In 2008, CIIC enacted the culture routes international charter, showed that culture routes had already been considered as the world's important research field.

Such many meetings and debates about cultural routes since 1994 ,proved that this new type of cultural heritage had attracted special attention by the national and international research field.

\section{Theoretic Context and System of Cultural Routes}

\section{Four Characteristics of Cultural Routes :}

In 1994, Madrid meeting discussed the following 4 points as a basis characteristics for the cultural routes as a world's cultural heritage type :

-Spatial characteristic :reflecting the fact of the length and space diversity communication;

-Time characteristic: reflecting the fact of only a certain period of time for the culture community's involution ;

-Cultural characteristic :reflecting the fact of crossing culture communication and contribution by the crowed ;

-Role and purpose characteristic : reflecting the fact that it has the function of playing a role in the cultural exchange, religious beliefs or trade. ${ }^{[4]}$

\section{Authenticity of Cultural Routes:}

In 2001,during the PamPlona Conference in Spain, CllC defined cultural routes should meet the criteria of authenticity, in order to clearly identify the authenticity of the cultural routes, based on the previous relevant documents.

In 2003 UNESCO once again clearly stressed the need to distinguish the Authenticity in its operating guide and draft as following: cultural route 's material form; cultural route's historical sense and its carried information and its important spiritual characteristics ; it should consider the relevant time factor and the use situation of various parts ; the legislative aspirations of the people who was affected by the cultural routes .

\section{Definition and Discrimination Scope of Cultural Routes :}

The definition of cultural routes should follow the three standards : ${ }^{[5]}$

-Space standards: the attributes of the line in space, including the space form ,important venue and monument,scope etc.

-Time standards: time of decline, frequency and intensity and its change of use, etc.

-Cultural standards :cultural standards emphasize culture influence on the routes ,including the purpose of the route, the type and amount of the exchange, and the impact of its influence on human memory and experience, etc.

The cultural routes has the features of overall and dynamic, natural and cultural combination and large scale and also multiple value levels systems .

\section{Four Basic Types of Cultural Routes:}

In the World Heritage List,cultural routes can be divided into the following 4 types: ${ }^{[6]}$

- Transportation routes: including the canal, and railway, such as Austria Semmering Mei Serlin Railway, India Darjeeling Railway, the French MIDI canal; 
- Trail routes :such as Oman Frankincense Trail;

- Religious Routes :such as Spain Route "santiago de eompostela";

- Linea Monuments :such as Fortifications and Defensive Structures, specific example is the the Great Wall in China, Hadrian the Great Wall in England, Defense Line of Amsterdam in Holland etc.

\section{The Enlightenment of Cultural Routes Theory to China Heritage Practice}

Facing the sustained boom and significant attention to world heritage's contradiction problem, culture routes no doubt provides a new choice with a kind of innovative concept to the world and China's heritage conservation, it achieves larger and wider range for heritage elements, provides more overall and more extensive protection mechanisms, seeks a win-win cooperation and sustainable development road to all the national, represents the cooperation mechanism from past to the future for all the countries in the world.

\section{Cultural routes provides integrity mechanisms concept to China heritage practice:}

The lines concept of cultural routes breaks through traditional thought in the heritage protection area ,giving shine light and new opportunity to Chinese overall heritage conservation .

The world cultural heritage protection concept has experienced from a single "point protection" such as bump unit to the "surface protection" such as historic blocks and historical towns protection, and then to the "routes protection" which links the "points protection" and the "surface protection" to a whole "linear environmental protection" process ,the concept of cultural routes perfectly combines all kinds of heritage conservation essences, from heritage elements ( points) to culture environments itself (surface), at the same time from the tangible environment conservation to the intangible environment conservation . ${ }^{[7]}$

\section{Cultural routes provides overall coordination management concept to China heritage management system :}

As a new kind of heritage type, cultural routes is characterized by integrity and coordination to a whole new management system and it changes the China heritage protection management system .

Cultural routes heritage management system has become a new international cooperation and global governance mode which is far more beyond the national and regional protection boundaries, the new management method with the joint declaration, joint protection and joint management makes all the China cultural routes parts area shared all the overall heritage interests. The establishment of CIIC largely promoted the spread to the global international integrity management system by cultural routes. Culture routes heritage concept promotes the regional sustainable development in China

Cultural routes heritage protection method promotes China area tourism resources legacy' development and utilization so as to promote area local economy and culture sustainable development.

Sustainable development has a close relationship with tourism development, cultural routes link the rich tourism resources along the different areas, the material and non-material heritages along the cultural route sites are the important protection nodes and important objects of tourism activities. The low value individual division tourism resources have no possibility to utilize and develop unless they are considered as part of cultural routes, cultural routes provides the most possibility to link all the lowed value and high value heritages together into a overall protection and developing system chain ,intend to promote the whole heritage protection and tourism development .The culture routes protection maintains a good interaction with China local culture and economic sustainable development.$^{[8]}$

\section{Conclusion}

(1) Cultural routes heritage concept has experienced a long process of arguments from proposing process to gradually improving process, more and more comprehensive linear heritage protection cases cause extensive attention by the world. 
(2) The emergence of this integrity protection concept has a profound social and cultural background which reflects a new heritage protection trend from single individual factor protection to overall environmental protection, and at the same time also reflects a new heritage protection trend from tangible protection to intangible protection. The overall concept of cultural routes contacts different elements heritage parts to a whole unit, fully embodies the cultural diversities and integrity protection along the routes.

(3) Cultural routes concept has dynamic, comprehensive, diverse and overall characteristics, it is not only a new world heritage type, but also is a new kind of international global cooperation governance mode with its unique integrate protection concepts and strategies.It set up a human major historical events with a specific culture clue and culture phenomenon,with its heritage' s comprehensive authenticity and integrity. It is changing the human civilization heritage protection history, seeking common historical memory, continuing local history cultural context and burnishing nationalist credentials.

(4) Culture routes protection comprehensively promotes China region's economic, social and culture sustainable development, at present, cultural routes heritage still needs all the world's continued and effective cooperation for extending and deepening its theory and practice.

\section{References}

[1] ICOMOS,Charter on Culture Route,ICOMOS 16th General, Quebec (2008)

[2] CIIC,Reports of Experts, http://international.icomos.org/madrid1994/cultural_routes (199411-09)

[3] UNESCO World Heritage Centre,Operational Guidelines for the Implementation of the World Heritage Convention ,http://www. Whc.unesco.org/archive/opguide05-en. Html (2005-02-02)

[4] Jianbo WANG, Yisan RUAN, Cultural routes as a heritage type - Interpretation of the ICOMOS Charter on Cultural Routes,CIIC , Journal of urban planning, no.4 (2009), in Chinese

[5] CIIC. 5th Draft of the ICOMOS Charter on Cultural Routes,http://international.icomos.org/ xi'an2005/charter/cultural_routes(2005-11-16)

[6] Zhou LV, Cultural routes: a new type of world heritage,Journal of Chinese Heritage(2006) in Chinese

[7] Wei LI, Kongjian YU,The new tendency of world cultural heritage - Cultural Routes , Urban Question, no.4(2005), in Chinese

[8] Yuxiang SHAN, Six grand trends of heritage conservation, China Daily,Beijing (2007-04-13),in Chinese 